\title{
The Application of Discovery Teaching in College Music Education Based on Marginal Utility and Regression Model
}

\author{
Zhihong Sun ${ }^{1}$, Junjie Liu ${ }^{1}$, Zheng Liu \\ ${ }^{1}$ Art Department, Hebei University of Technology, TianJin, China \\ s_un_zhihong@126.com \\ ${ }^{2}$ Department of Arts Management, Tianjin Conservatory of Music, TianJin, China
}

Keywords: discovery teaching; marginal utility; expert assessment method; music education in college

\begin{abstract}
So this article explains the application of discovery teaching in college education in different aspects. The utility and marginal utility functions have been built in this article to find out the perfection node of ability of students identifying problems and solving problems. At the same time, four aspects and three stages of discovery teaching have been raised. In this article we set up a four in one linear regression function by using the example of vocal music teaching. We also use the expert assessment method to analyze and get effect of discovery teaching and then the application analysis of the discovery teaching in college music education.
\end{abstract}

\section{Introduction}

The discovery teaching was raised by psychologist Jerome S Bruner from Cognitive School of US. He stressed the initiative of human beings and believed that we shouldn't regard people as the passive recipients. The discovery teaching asks the teachers to provide more materials to make the students find the results and laws by themselves. Its aim is to develop students' exploration and thinking ability. The students can derive the unknown from the practice, form the concept, find the development rules of the things, cultivate the scientific attitude and creation spirit of the students and master the scientific research methods.

With the development of the economy, people pay more attention to the spiritual needs, for example, the aesthetics tends to diversify. Now the traditional music education system can't meet the present needs. Therefore, the reform of it is imperative. The discovery teaching focuses on cultivating the students' creation and practice ability, encourage students to find problems, analyze problems, solve them and practice (the process of discovery teaching). In this way, students can feel the charm of the music actively.

\section{Establishing Marginal Utility Function and Utility Function}

A. The Utility and Marginal Functions of the Students Attraction to the Problems

Set the attraction of the problems to the students $y_{1}$ as the dependent variable, the perfection (the integrity, independence and ideological content) of the music as the independent variable and then establish the utility function

$$
y_{1}=f\left(x_{1}\right)
$$

The increase of each of the integrity, independence and ideological content of the music will lead to the increase of the attraction, which means that (1) is an increasing function. When the perfection of the music continuously increases, the attraction of the problems to the students will increase; and when the perfection of the music reaches certain level, the cognition of the students to the problems will be more comprehensive. For example, when a person is thirsty, he will feel very effective when he drinks the first saliva. With the amount of the water he drinks, although the total utility is increasing, actually the marginal utility that each saliva he drinks is declining. When he doesn't feel thirsty, the total utility is reaching maximum, but the marginal utility is declining to zero. If he continues to drink, he will feel uncomfortable. That means the marginal utility declines to negative value and the total utility is therefore declining. Similarly, when the perfection of the music continues to increase, the marginal attraction of the music problems to the students 


$$
y_{1}^{\prime}=\frac{d y_{1}}{d x_{1}}
$$

will continuously decline, which is the expression of the marginal utility decline law in economics. B. The Utility Function and Marginal Utility Function of Ability of the Students Solving Problems

Set the ability of students solving problems $y_{2}$ as the dependent variable and the comprehensive quality of the students (including EQ and IQ) $x_{2}$ as the independent variable and then establish the utility function

$$
y_{2}=f\left(\mathrm{x}_{2}\right)
$$

and the marginal utility function of solving problem ability of the students

$$
y_{2}^{\prime}=\frac{d y_{2}}{d x_{2}}
$$

When the comprehensive quality of the students is better, the solving problem ability $y_{2}$ is bigger. When $y_{2}$ reaches a certain level, the students will require more perfection of the ability of solving problems and the value of the marginal utility function is decrease progressively.

C. Finding the Perfection Node of the Students Solving Problems and Identifying Problems

In order to develop the discovery teaching, we hope the students can coordinate ability of identifying problems with the ability of solving problems. That means that the total utility of the problem attraction to the students and the total utility of the ability of student solving problems should reach the consistent maximum. Due to the marginal utility decline law, the same total utility may correspond to different investment and corresponding marginal utility values.

By the discovery teaching, we get the questionnaire of performance of the opera in the music education and then get the data of total utility and marginal utility in the different performance levels, which is shown below,

TABLE I. TOTAL UTILITY AND MARGINAL UTILITY

\begin{tabular}{|l|l|l|}
\hline Level of Performance & Total Utility & Marginal Utility \\
\hline 0 & 0 & \\
\hline 1 & 10 & 10 \\
\hline 2 & 18 & 8 \\
\hline 3 & 24 & 6 \\
\hline 4 & 28 & 4 \\
\hline 5 & 30 & 2 \\
\hline 6 & 30 & 0 \\
\hline 7 & 28 & -2 \\
\hline
\end{tabular}

Taking the level of performance as the horizontal axis and the total utility as the vertical axis, Figure 1 of total utility is got.
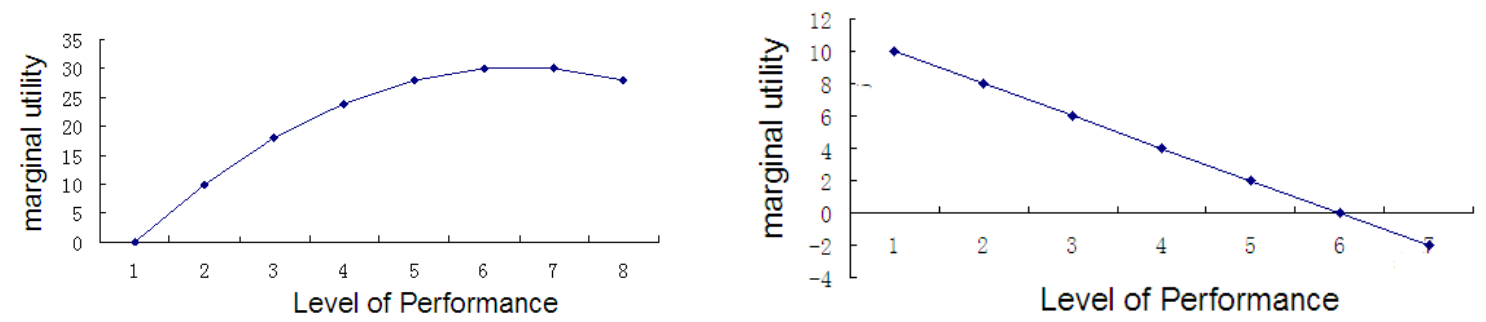

Figure 1. The Graph of Total Utility in Different Level of Performance

Figure 2. The Graph of Marginal Utility in Different Level of Performance

From this figure, when the total utility is 28 or 30, we have two levels of performance. To solve the problems of opera performance, the performance should be coordinated with other factors of the opera. If you just pay much attention to one aspect, you may work fruitlessly and even influence the overall performance of the opera.

Taking the level of performance as the horizontal axis and the marginal utility amount as the vertical axis, figure 2 of marginal utility is got.

Using Matlab to have data difference fitting in Fig. 1, the utility function of the problem attraction to the students can be got as below.

$$
y=-x^{2}+12 x
$$

And the marginal utility function is as below.

$$
y=-2 x+12
$$


To sum up, we seek the perfection node of the students identifying problems and solving problems means that when the total utility of the problem attraction to the problems and that of the ability of students solving problems unanimously reach to the maximum, the perfection node is located in the curves when the corresponding marginal utility value is more ore equal to zero.

\section{The Analysis of the Application of Discovery Teaching}

People have different needs to the music in different periods, and the society will have different needs to the music. In $20^{\text {th }}$ century, the traditional music education mode played an inevitable role, but when entering $21^{\text {st }}$ century, the diversification of the world results in many problems caused by the inadaptation of traditional education mode, such as poor practice ability, lack of creation, and poor ability of research and comprehensive quality. Our students can not keep the pace of the times. So the reform is imperative.

Four aspects and three steps of the reform is listed below,

Four Aspects

To adapt to the needs of the age and complete the college music education mode

To provide more chances to cultivate the students ability of practice

To combine the teaching with the research and cultivate the students ability of creation

To improve the students ability of academic research

Three Stages

(1) The first year of university: Laying a solid foundation

Due to the lack of the ability of identifying and solving problems independently, the freshmen should be cultivated to have the ability of cooperation.

(2) The second and the third year of university: Improvement

After one year study, the students may have inquiry ability. In the second and third year, we should increase the difficulty of the problems, expand the scope of the problems and ask the students to have some proper music practice.

(3) The fourth year of university: Practice

After the above two stages, the students can identify the new problems, raise new ideas and do the scientific research. So in this stage, we should ask the students to perform, rehearse and direct so as to adapt to the work.

The discovery teaching has different impacts on the above four aspects and three stages and the more impacts of the teaching methods provide, the more benefit the college music education can get. Finally the discovery teaching can be perfectly get immersed into the college music education and the qualified talents can emerge. We suppose the effectiveness of the discovery music teaching is $Z$; $t_{1}$ is the learning time; $t_{2}$ is the ability of analyzing problems; ${ }^{t_{3}}$ is the ability of solving problems; and $t_{4}$ is the practice ability. In this article, we use $Z$ as dependent variable and $t_{1}, t_{2}, t_{3}, t_{4}$ as the independent variables to establish a four in one linear regression function, which is as follows,

$$
z=\omega_{1} t_{1}+\omega_{2} t_{2}+\omega_{3} t_{3}+\omega_{4} t_{4}
$$

$\omega_{1}, \omega_{2}, \omega_{3}$ and $\omega_{4}$ are respectively the weights and should satisfy

(6) which is

$$
\omega_{1}+\omega_{2}+\omega_{3}+\omega_{4}=1
$$

The discovery music teaching requires learning time, the ability of analyzing problems, the ability of solving problems and practice ability differently, which leads to the different contribution rates of the discovery music teaching to the four aspects. We use expert assessment method to assure the weights $\omega_{1}, \omega_{2}, \omega_{3}$ and $\omega_{4}$.

In order to analyze the application of the discovery teaching in college music education, in this article we take the vocal teaching as an example to have a test and the data is shown below

\begin{tabular}{|l|l|l|l|}
\hline \multicolumn{4}{|c|}{ TABLE II. } \\
\hline Learning Time & The Ability of Analyzing Problems & The Ability of Solving Problems & Practice Ability \\
\hline $25 \%$ & $34 \%$ & $82 \%$ & $68 \%$ \\
\hline
\end{tabular}

Then we invite 3 experts to assess the 4 indications as following steps:

Step1: Inviting each expert to score 4 indications and assuring the total score of the 4 indications is 100 ;

Step 2: Calculating the average of each indication and the result shown in Table 3; 


\begin{tabular}{|c|l|l|l|l|}
\multicolumn{4}{c|}{ TABLE III. } & \multicolumn{1}{c|}{ THE ASSESSMENT RESULT FROM EXPERTS } \\
\begin{tabular}{|c|l|l|l|l|}
\hline Indication & Expert A & Expert B & Expert C & The Average Value \\
\hline Learning Time & 40 & 10 & 20 & 23.33 \\
\hline The Ability of Analyzing Problems & 10 & 30 & 20 & 20 \\
\hline The Ability of Solving Problems & 20 & 40 & 35 & 31.67 \\
\hline Practice Ability & 30 & 20 & 25 & 25 \\
\hline
\end{tabular}
\end{tabular}

Step 3: Calculating the weight of each indication

The weight of Learning time is $\omega_{1}=\frac{23.33}{100} \approx 0.23$

The weight of the ability of analyzing problems is $\omega_{2}=\frac{20}{100} \approx 0.20$

The weight of the ability of solving problems is $\omega_{3}=\frac{31.67}{100} \approx 0.32$

The weight of practice ability is

$$
\omega_{4}=\frac{25}{100} \approx 0.25
$$

And the weighted relation we got should satisfy (6).

Put the data in Table 2 and Table 3 into formula 5, then the application effectiveness of discovery teaching in vocal education is as below,

$$
\begin{aligned}
z & =0.23 \times 25 \%+0.20 \times 34 \%+0.32 \times 82 \%+0.25 \times 68 \% \\
& =0.5579
\end{aligned}
$$

This indicates that the effect is visible and also further shows that significance of the application of the discovery teaching in college music education.

\section{Conclusion}

With the diversification of the society, the people's needs to music are diversifying, which results in the disjunction between the traditional college music education mode and the new situation. So the reform is imperative. Based on the four aspects and three stages raised in this article, the application of the discovery teaching in the college music education has been discussed from the perspective of the mathematics. The utility and marginal utility functions have been built in this article to find out the perfection node of ability of students identifying problems and solving problems. At the same time, four aspects and three stages of discovery teaching have been raised. In this article we set up a four in one linear regression function. We also use the expert assessment method to analyze the examples, and get effect of the application of the discovery teaching in college music education.

\section{References}

[1] Zheng Xin The Problems and Strategy of "Discovery” Teaching Method in Music Educaion, Rural Development, 2010

[2] Wang Suyu, The Application of Discovery Teaching Mode, Bulletin of Biology, 1996(10): 3536

[3] Gao Hongye, Western Economics [M], Beijing, Renmin University of China Press, 2007

[4] Wang Yuan, The New Mode of Normal Music Education Constructed by Using Scientific Concept of Development, Southwest University of Nationalities Journal, 2007 (4):228-231.

[5] Chen Wangheng, The Aesthetics of Art and Design [M], Wu Han, Wuhan University Press, 2000

[6] Lin Hua, Computer Graphic Art Design [M], Beijing, Tsinghua University Press, 2005

[7] Zhu Dongsheng, Thought of Normal Music Education in 21st Century, Music of China, 2001(3):47-49.

[8] Liu Xiaoxu, The Comparison between Grey Forecasting and A linear Regression Forecasting, Sichuan Institute of Technology Journal, 2009 (1):107-109. 